\title{
The Role of $11 \beta$-Hydroxy Steroid Dehydrogenase Type 2 in Glucocorticoid Programming of Affective and Cognitive Behaviours
}

\author{
Fraser J.G. Shearer ${ }^{a, b}$ Caitlin S. Wyrwoll ${ }^{c}$ Megan C. Holmes ${ }^{a, b}$ \\ ${ }^{a}$ Centre for Cardiovascular Science, Queen's Medical Research Institute, The University of Edinburgh, Edinburgh, UK; \\ ${ }^{b}$ Centre for Cognitive Ageing and Cognitive Epidemiology, The University of Edinburgh, Edinburgh, UK; \\ 'School of Anatomy, Physiology and Human Biology, The University of Western Australia, Perth, WA, Australia
}

\section{Keywords}

$11 \beta$-Hydroxysteroid dehydrogenase - Placenta · Fetus .

Brain · Glucocorticoids · Behaviour

\begin{abstract}
Developmental exposure to stress hormones, i.e. glucocorticoids, is central to the process of prenatal programming of later-life health. Glucocorticoid overexposure, through stress or exogenous glucocorticoids, results in a reduced birthweight, as well as affective and neuropsychiatric outcomes in adults, combined with altered hypothalamus-pituitary-adrenal (HPA) axis activity. As such, glucocorticoids are tightly regulated during development through the presence of the metabolizing enzyme $11 \beta$-hydroxysteroid dehydrogenase type 2 (HSD2). HSD2 is highly expressed in 2 hubs during development, i.e. the placenta and the fetus itself, protecting the fetus from inappropriate glucocorticoid exposure early in gestation. Through manipulation of HSD2 expression in the mouse placenta and fetal tissues, we are able to determine the relative contribution of glucocorticoid exposure in each compartment. Feto-placental HSD2 deletion
\end{abstract}

(c) 2019 S. Karger AG, Basel

E-Mail karger@karger.com www.karger.com/nen resulted in a reduced birthweight and the development of anxiety- and depression-like behaviours in adult mice. The placenta itself is altered by glucocorticoid overexposure, which causes reduced placental weight and vascular arborisation. Furthermore, altered flow and resistance in the umbilical vessels and modification of fetal heart function and development are observed. However, brain-specific HSD2 removal (HSD2BKO) also generated adult phenotypes of depressive-like behaviour and memory deficits, demonstrating the importance of fetal brain HSD2 expression in development. In this review we will discuss potential mechanisms underpinning early-life programming of adult neuropsychiatric disorders and the novel therapeutic potential of statins.

(c) 2019 S. Karger AG, Basel

\section{Prenatal Glucocorticoids Programme Later Life Health}

The notion that the prenatal environment can affect the lifetime health of a fetus is well established though not entirely understood mechanistically. Since the initial ob- 
servation that birthweight, a readily accessible proxy of prenatal health, positively correlates with cardiovascular health in adulthood, a revolution in how we think about the origins of health outcomes began [1]. In the decades since Barker [1] first described this phenomenon, the repertoire of adult conditions linked to a low birthweight and prenatal life has expanded to include a range of neuropsychiatric disorders. The prevalence and complex aetiology of neuropsychiatric disorders make the possibility of a common root in the prenatal environment a tantalizing treatment window. A low birthweight has been found to be associated with an increased risk of affective and anxiety disorders [2], behaviour and attention disorders [3,4], a lower IQ [5], schizophrenia [6, 7], and autism spectrum disorder [8]. Amongst the many factors that affect birthweight, stress hormones - glucocorticoids - have emerged as candidates for mediating the programming effects, through observations that maternal stress during pregnancy causes a low birthweight and increases the risk of later-life neurological disorders $[9,10]$. Animal models have further indicated that excess glucocorticoids in pregnancy have detrimental effects on neurodevelopment $[9,11-14]$.

During pregnancy, glucocorticoid levels increase from trimester to trimester until serum levels are up to 3 times that of pre-pregnancy [15], in part to facilitate essential maternal adaptations. There is a complexity to this rise in circulating maternal glucocorticoids, however, as circulating corticosteroid-binding globulin and its affinity for glucocorticoids also vary during pregnancy [16], thus regulating free glucocorticoid levels and action. Conversely, the fetus is maintained in a glucocorticoid environment 5-10 times lower than the maternal circulation until the last stages of gestation, at which point a surge in glucocorticoids aids the maturation of organs by promoting cell differentiation and the arrest of proliferation in preparation for the ex utero environment $[17,18]$. This is most notable in the case of the lungs, where the formation of surfactant is reliant on glucocorticoids. Consequently, babies likely to be born prematurely (at 24-37 weeks) are administered synthetic glucocorticoids (such as dexamethasone or betamethasone) to induce lung maturation early and increase survival $[17,19]$.

Given the potent effects of glucocorticoids on fetal development, it is critical that fetal glucocorticoid exposure be tightly regulated. This regulation is achieved in part through the presence of $11 \beta$-hydroxysteroid dehydrogenase type 2 (HSD2), an NAD-dependent enzyme which converts active, receptor-binding glucocorticoids to their inactive forms in the cytoplasm [18]. The sister glucocor- ticoid metabolizing enzyme HSD1 is also expressed in the placenta. It converts inactive 11-keto derivatives to the active glucocorticoid, therefore raising active glucocorticoid levels [18]. HSD1 is expressed in the labyrinth zone of the rodent placenta in late gestation (rising as HSD2 levels fall), potentially increasing glucocorticoids reaching the fetus to induce terminal differentiation before parturition [18]. It is the protective barrier of HSD2 that will be investigated further in this review.

\section{Two Hubs of HSD2 Limit Fetal Exposure to Glucocorticoids}

In the adult organism, the role of HSD2 is primarily to protect mineralocorticoid-responsive tissue from inappropriate binding of glucocorticoids to mineralocorticoid receptors (MR), for which they have a high affinity [18]. For example, HSD2 is highly expressed in the distal nephron of the kidney, where MR activation by aldosterone is required for sodium reabsorption. However, during gestation, HSD2 is much more widely expressed in the fetus and the placenta. Fetal expression of HSD2 is widespread but transient. In the mouse, HSD2 is expressed in the majority of fetal tissues until E13.5, when a rapid decline in expression is observed [20]. The expression of HSD2 in the brain declines after mid-gestation but is maintained in discreet pockets into the third trimester, after which it further declines, with early postnatal expression restricted to the thalamus and the cerebellum in the rodent [20-22]. In the placenta HSD2 is expressed in the syncytiotrophoblast, where maternal and fetal circulations are in apposition $[18,20,23]$. Only the fetal side of the placenta expresses HSD2 and its expression declines along a similar timeline similar to that of fetal HSD2 [18, 20]. In early-gestation placental HSD2 regulates fetal exposure to maternal glucocorticoids [24]. Interestingly, when HSD2 is inhibited, cortisol does not freely perfuse across the placenta [25], highlighting the likely contribution of transporters, potentially adenosine triphosphate-binding cassette $(\mathrm{ABC})$ transporters, to protection of the fetus from elevated cortisol [26-28]. Furthermore, the regulatory activity of HSD2 is somewhat malleable. Elevated glucocorticoids, such as occur during stress, can increase the fetal exposure by overwhelming and downregulating HSD2 activity [29, 30]. Additionally, in the case of glucocorticoid treatment, synthetic glucocorticoids (see above) are poor substrates of HSD2, and as such they are not inactivated. Importantly, the downregulation of HSD2 consistently elicits fetal 
growth restriction and is strongly associated with adverse health outcomes in later life, highlighting that feto-placental HSD2 is a critical mediator between the neonatal environment and adult outcomes.

Mutations of HSD2 in the human population lead, most notably, to the syndrome of apparent mineralocorticoid excess through the unrestricted binding of glucocorticoids to MR in the distal tubules of the kidney [31]. The majority of these mutations lie in the $\mathrm{COOH}$ terminus half of the gene [18]. Polymorphisms of the HSD2 gene (HSD11B2) have been investigated in relation to neuroaffective disorders. A study of schizophrenia risk in relation to HSD2 genotype found an interaction between early-life stress exposure and the rs5479 genotype in children aged 3-9 years which conveyed an increased risk of the disorder [32]. In a prospective study of cortisol in pregnancy, the functional HSD11B2[CA]n polymorphism in fetuses was shown to be associated with increased maternal cortisol [33].

Hence, manipulation of HSD2 expression in mice provides a platform for examining the effects of early glucocorticoid exposure on the fetus without artificially elevating glucocorticoids. This also enables control of the site of premature glucocorticoid exposure to the mother, the feto-placental unit, or the fetus alone. Homozygous matings of $\mathrm{HSD}^{-/-}$mice generated offspring with a low birthweight and reduced neonatal cerebellar growth, and as adults they exhibited the syndrome of apparent mineralocorticoid excess and a depressive and anxious phenotype [10]. Heterozygous mating of these mice, giving 3 genotypes of offspring in the same litter $\left(\mathrm{HSD}^{+/+}, \mathrm{HSD}^{+/-}\right.$, and $\mathrm{HSD} 2^{-/-}$), found no significant differences between heterozygous mice and $\mathrm{HSD} 2^{+/+}$mice, illustrating that the maternal phenotype did not influence the offspring and that reduction of the placental barrier to $50 \%$ failed to alter fetal outcomes [10]. However, HSD2 ${ }^{-1-}$ mice are exposed to glucocorticoids at an inappropriate time in gestation, as they lack placental and fetal protection. In this genotype, the birthweight is reduced, highlighting that glucocorticoids do affect development [10, 34]. Furthermore, as adults $\mathrm{HSD} 2^{-/-}$mice display an anxiety-like phenotype in both open-field and elevated plus maze assessments [10] and depression-like behaviour in tail suspension and forced swim tests [35].

Dysfunction of the HPA axis is commonly seen in offspring following prenatal stress exposure, and furthermore is often considered a marker of prenatal stress [36]. However, while $\mathrm{HSD}^{-/-}$offspring exhibit behaviours classically associated with HPA axis dysfunction, no changes in the HPA axis have been observed [10]. HSD2 expression in the adult mouse brain is limited to the nucleus tractus solitarius, where it maintains the aldosterone selectivity of MR [37]. The majority of glucocorticoid effects on the brain in HSD2 $2^{-/-}$are, therefore, likely developmental in origin. The global knockout of HSD2 provides an insight into the role that the HSD2 plays in neurodevelopment and programming of adult behaviour, but the phenotypes observed, though likely to involve neurodevelopment, are confounded by the effects of HSD2 removal from other body systems in the adult. Furthermore, deletion of HSD2 in the fetus generates an AME phenotype of increased blood pressure [10] together with an increased salt appetite mediated by the loss of HSD2 in the brain [38]. Additionally, HSD2 ${ }^{-1-}$ does not provide a distinction between the 2 hubs of HSD2 expression in gestation, i.e., the placenta and the fetus. The relative importance of the 2 hubs of HSD2 expression in development in the programming of neurological conditions are discussed below (Fig. 1).

\section{The Placenta Orchestrates Fetal Development and Adult Health Outcomes}

The placenta is the interface between the mother and the fetus regulating nutrient and waste transfer and endocrine and immunological responses, thus ensuring maternal adaptations and fetal development. These placental functions are by no means passive and the placenta has a remarkable plasticity, capable of adaptations to mitigate an adverse in utero environment. Furthermore, the fetal sex influences the plasticity of the placenta [39]. If normal placental function or adaptation is overcome, this can result in poor fetal outcomes such as intrauterine growth restriction (IUGR). However, the ramifications of inadequate placental function extend far beyond short-term health outcomes. Epidemiological and animal studies have shown that reduced placental function and weight are associated with a low birthweight and an increased risk of cardio-metabolic and neuropsychiatric outcomes in adult life [40] (Fig. 1a). However, despite the critical importance and dynamic responses of the placenta, it remains under-researched and poorly understood.

The placenta has an influential role in fetal brain development. IUGR, of which placental function is the major determinant, is associated with adverse neurodevelopmental outcomes. Children born following IUGR have a greater chance of cognitive impairment at school age (affecting boys more) [41] and a delay in fetal behavioural milestones [42]. Furthermore, a recent retrospective 
Fig. 1. Tissue-specific HSD2 deletion models inform on mechanisms underpinning glucocorticoid programming of adult neuropsychiatric disease. a Global HSD2 knockout mice. b Brain-specific HSD2 knockout mice.
Adult neurobehavioural phenotype

- Depression-like behaviour

- Anxiety-like behaviour

- Altered serotonergic and catecholamine pathways

a

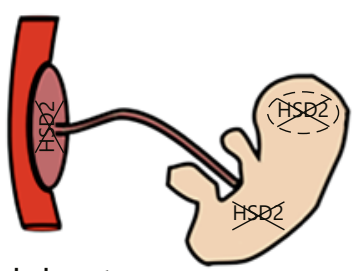

Placental phenotype

- Reduced vascularization

- Reduced expression of angiogenic factors

- Reduced placental size

Other phenotype

- Elevated adult blood pressure

- Apparent mineralocorticoid excess

- Reduced birthweight
Adult neurobehavioural phenotype

- Depression-like behaviour

- Memory deficit

- Reduced hippocampal S-HT1A expression

b

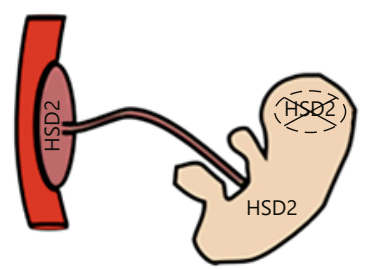

study of placental MRI data found an association between a reduced placental apparent diffusion coefficient and fetal CNS pathology [43]. In animal models of IUGR, a reduced blood flow to the placenta has been found to cause a variety of structural and behavioural changes in rodents [44]. Additionally, in genetic mouse models where lethality occurs before E14.5, a placental deficit is common and correlates with neurodevelopmental and cardiovascular defects in the embryo [45]. Moreover, the placenta contributes directly to brain development through transport and synthesis of serotonin in early gestation [46]. This source of serotonin supports forebrain development in the period prior to the complete arborisation of Raphe nuclei neurones in the fetal brain. The placenta has a complicated genetic make-up that includes genes from the fetus and imprinted genes from both parents. Glucocorticoids can alter gene expression through epigenetic changes. Interestingly, female placentas are less sensitive to these effects than males which could provide a basis for the sexually dimorphic penetrance of neurodevelopmental diseases which are regularly more prevalent in males $[47,48]$. Recent work has suggested that the resilience of the female hypothalamus and the HPA axis to prenatal stress is down to high levels of histone $\mathrm{H} 3$ methylation in the female placenta [47]. Perhaps most relevant is the robust finding that glucocorticoids downregulate placental HSD2 $[29,30,49,50]$. This, coupled with the increase in placental CRH creates something of a positive feedback loop that acts to further increase fetal glucocorticoid exposure.

\section{Glucocorticoids Alter Placental Function}

As outlined above, the placenta regulates the transfer of glucocorticoids between the mother and the fetus in the early stages of pregnancy. Classically, the primary focus of the adverse effects of glucocorticoids on fetal development is argued in the context of disruption in placental HSD2, leading to direct effects of glucocorticoids on fetal tissues. While this is true, the placenta itself, however, is also sensitive to elevated glucocorticoids. Thus, given that placental function is a critical regulator of fetal growth and development, an aspect of the adverse effects of elevated glucocorticoids on fetal outcomes must be due to perturbations within the placenta itself. Indeed, placental angiogenesis of fetal capillaries is markedly downregulated in animal models of glucocorticoid excess, possibly through downregulation of angiogenic factors such as vascular endothelial growth factor A and PPARy [51, 52]. Similarly, the removal of HSD2, while increasing the exposure of the fetus to glucocorticoids, also increases the exposure of the placenta. This increased placental exposure to glucocorticoids also manifests in a marked reduc- 
tion of fetal capillary development at the end of gestation, which decreases the nutrient and waste exchange capacity of the placenta [53]. Furthermore, this reduction in fetal capillary development is accompanied by a reduced umbilical cord flow and an altered nutrient transport, thus contributing to the reduction in fetal weight of $\mathrm{HSD}^{-/-}$offspring [53] and in turn affecting fetal cardiac function in HSD2 $2^{-/-}$offspring [54]. The neurodevelopmental phenotype at this stage of gestation, including any fetal brain haemodynamic changes, remains to be characterized. It is an important consideration, however, as it may give further insight into the mechanisms underlying the behavioural phenotype of adult HSD2 ${ }^{-/}$offspring.

Strikingly, the reduced fetal-placental capillary development and weight and the altered cardiac phenotype of the HSD2KO fetuses can be rescued by administration of pravastatin [54]. Pravastatin is an HMG-CoA reductase inhibitor approved for use in lowering LDL-cholesterol [55], which has also been shown to increase the serum levels of vascular endothelial growth factor in a mouse model of preeclampsia [56], as well as elevating placental expression in our HSD2 $2^{-/}$model [54]. Whether the ameliorating effects that pravastatin has on vascular and growth parameters in the face of glucocorticoid excess extend to the neurological phenotype of $\mathrm{HSD}^{-/-}$mice remains unknown. Encouragingly, a recent study of pravastatin in a model of preeclampsia found that the drug prevented the long-term health effects of the model on the offspring of pre-eclamptic pregnancies, including reduced brain microglia activation at P10 [57].

While these studies have highlighted the importance of feto-placental HSD2 in determining placental function, fetal growth, and later life outcomes, they have not definitively ascribed a specific role of placental HSD2 in these associations. This is as HSD2 is absent from both placental and fetal tissues and, as such, the relative influence of each of these compartments and the potential for cross-talk cannot be teased apart in $\mathrm{HSD} 2^{-/-}$fetuses. Furthermore, the confounding effects of the absence of HSD2 in the offspring kidneys, as discussed above, obfuscates our association between early-life HSD2 absence and later health outcomes. To overcome this, we need to investigate the effects of specific removal of placental HSD2 on neonatal and adult phenotypes, as well as the effects of the specific removal of HSD2 from the fetal brain (HSD2B$\mathrm{KO}$ ). We have developed both of these models in our laboratory and, while the model of placental HSD2 removal is still being characterized, our findings on HSD2BKO highlight some implications for early-life neural glucocorticoid exposure in determining brain outcomes.

\section{Specific Effects of Prenatal Glucocorticoids on the Fetal Brain}

To determine the role of inappropriate glucocorticoid overexposure (both timing and magnitude) within the developing fetal brain, we generated a brain-specific knockout of HSD2 (HSD2BKO) [58] (Fig. 1b). The consequences of HSD2 deletion in the brain will be largely developmental (only one discreet region of adult mouse brain, i.e., the nucleus tractus solitarius, expresses HSD2, which is involved in salt appetite and blood pressure [54]) and hence serves to show the relevance of fetal HSD2 in neurodevelopment, independently of the placental HSD2. In this model, at E15.5 glucocorticoids are elevated in the HSD2BKO fetal head but they are no different from controls in the rest of the body; this difference normalizes again by E17.5 when the HSD2 expression naturally declines in controls $[20,58]$. In this model, some aspects of the global HSD2 knockout and other models of prenatal glucocorticoid excess are recapitulated. Thus, HSD2BKO mice present with depression, a mild memory deficit, and a decreased 5-HT1A receptor expression in the adult hippocampus. They do not, however, exhibit anxiety-like behaviour which is pronounced in global HSD2 $2^{-/}$offspring. No alterations in HPA axis function have been observed in this model, nor do birthweights differ between knockouts and littermate controls. This first and foremost demonstrates that fetal brain HSD2 has an important role in neurodevelopment and further that glucocorticoids can exert an effect on the fetal brain even when the placental HSD2 barrier and circulating fetal glucocorticoids are unaffected. Thus, the focus on the relative importance of placental HSD2 acting as a "protective barrier" needs to be widened (or even questioned) to take into consideration the significance of fetal tissue HSD2. However, given that the global knockout phenotype is only partly recapitulated by removing HSD2 from the fetal brain suggests that there is a role for placental HSD2 expression in influencing aspects of brain development and function. Conversely, it may be that the absence of renal HSD2 is responsible for the anxiety in $\mathrm{HSD}^{-/-}$offspring.

\section{HSD2 and Sex Differences}

Given that prenatal stress has a sex specific effect on the behaviour of offspring, with male offspring being more susceptible to affective behaviours than females, the mechanism underpinning these effects is questionable. In The Placenta Orchestrates Fetal Development and Adult 
Health Outcomes, we argued that the placental structure and function are differentially affected by stress in male and female fetuses, i.e., male fetuses respond to stress more poorly and have poorer disease outcomes than females. Human females born $72 \mathrm{~h}$ after glucocorticoid administration had increased placental HSD2 expression compared to males [59], suggesting that females have a protective mechanism against stress and glucocorticoid exposure. One mechanism underpinning the downregulation of HSD2 in response to social adversity is increased methylation of placental HSD11B2, particularly in male placentas [60]. In a rodent model of prenatal stress, placental Hsd11b2 mRNA was decreased and methylation of the promoter increased. However, altered methylation of the Hsd11b2 promoter region was observed in some brain regions with little effect on Hsd11b2 mRNA levels [30]. In this study no sex-specific effects of maternal stress on Hsd11b2 expression or DNA methylation were observed, but this study may be underpowered to observe these differences. Intriguingly, placental methylation levels did predict corresponding changes in the brain. Due to the importance of sex differences for the programmed phenotype, it is essential that more work be done on sex differences in the HSD2 and other programming models.

\section{Prenatal Glucocorticoids Cause Long-Lasting Alterations to the Serotonin System}

A common thread linking the affective phenotypes seen in the HSD2 knockout models, glucocorticoids, and the role of the placenta in development is serotonin. In development, serotonin has a crucial role to play in the fetal brain. It supports cell growth, survival, migration, and guidance of axons [61]. Mice lacking serotonin in the central nervous system display increased anxiety and aggression, though there are no obvious structural abnormalities in the brain $[62,63]$. In early development, the fetal brain expresses serotonin receptors, though it does not yet produce its own serotonin. There are, however, measurable levels of serotonin and serotonin activity at this time, the source of which is the placenta. Thus, the placenta transports serotonin from maternal circulation and produces it in a temporal fashion, supporting the development of the fetal forebrain until the serotonin neurones of the Raphe nuclei are fully developed [46]. In $\mathrm{HSD}^{-/-}$mice, serotonin levels are elevated in diencephalic regions of the adult male brain [35]. In the HSD2BKO model, depressive-like behaviours are accompanied by downregulation of the serotonin receptor 5-HT1A in the hippocampus, an effect also seen in the HSD2 $2^{-/-}$ model and in prenatally stressed rats [64]. This receptor is downregulated by glucocorticoids in a number of species and under normal conditions it has a complex time course of expression [65-67]. The timing of glucocorticoid exposure is critical to determining the effects that the steroids have on development. Thus, the coincidence of elevated glucocorticoids and expression of glucocorticoid-regulated 5-HT1A receptors [68] may be a determinant factor in the programming of serotonin-mediated affective disorders in later life. How glucocorticoid exposure affects the placental serotonin system is unknown but it could be crucial to understanding the interplay of these 2 factors in development. Indeed, expression of the serotonin transporter in the placenta has been shown to be related to infant regulatory behaviours but not maternal depressive symptoms [69]. Moreover, by inducing insulin receptor deficiency in the placentas of mice, Bronson et al. demonstrated a reduced expression of the serotonin-related genes TPH1 and SLC6A4 in male placentas at E12.5, accompanied by reduced sensorimotor gating in the prepulse inhibition test and an increased HPA axis response to stress in the adult [70].

\section{Conclusions}

\section{The Specific Roles of Placental HSD2 and Fetal HSD2}

Are Not Yet Clear

HSD2 clearly protects the fetus from the deleterious effects of inappropriate glucocorticoid exposure. This has been confirmed in clinical and preclinical experiments; whether HSD2 is inactivated, removed, or bypassed, fetal and later-life health is affected. Expression of prenatal HSD2 is found in the placenta and throughout the fetus itself. Fetal HSD2 is often ignored in the literature, with discussions focused on the protective role of the placenta; however, it is now clear from tissue-specific knockout of fetal HSD2 that, while it is important, placental HSD2 is not the entire story in defending the fetus from early glucocorticoid exposure. Placental dysfunction following glucocorticoid exposure has been experimentally linked to neurodevelopmental disorders, but depression-like behaviour can be induced in mice by removing HSD2 just from the fetal brain. This suggests specific pathways to disease that are defended differentially by the different compartments of HSD2 expression. Specific removal of HSD2 from the placenta will be necessary to determine whether this is the case. Strikingly, pravastatin treatment can reverse the placental vascular phenotypes observed in 
the global HSD2 knockout model. How this drug might affect the brain-specific knockout is not yet known. In a model of preeclampsia - the C1q knockout mouse - cardiovascular outcomes for both the mother and the fetus were improved by pravastatin [57], suggesting that its effects are long lasting. However, further investigation will be required to determine whether it can affect neuropsychiatric phenotypes.

\section{HSD2 Expression Protects the Serotonin System in \\ Development}

The neurological phenotypes that result from inappropriate fetal glucocorticoid exposure may involve the serotonin system. Glucocorticoids interact with serotonin in development and the serotonin receptor 5-HT1A is downregulated in the absence of HSD2 activity in the fetal brain. The persistence of this effect in the adult brain and the role that serotonin has to play in affective disorders suggest that it may be crucial to the programming of these disorders by glucocorticoids. Further investigation is necessary to ascertain how precisely serotonin signalling is altered and what effect this has on brain development. Moreover, the placenta supports the serotonin-mediated development of the fetal forebrain in early gestation at a time when the fetus particularly vulnerable to environmental assault. Should serotonin be central to the programming effects of glucocorticoids, the differential role of each compartment may be linked to how serotonin is affected in each of these compartments.

HSD2 is undoubtedly essential for the protection of the fetus during gestation. The placenta is central to development and its expression of HSD2 not only shields the fetus but also protects the placenta itself from the deleterious effects of glucocorticoids. It is becoming increasingly clear, however, that fetal expression of HSD2 is also necessary for the proper regulation of fetal glucocorticoid exposure. The serotonin system seems particularly vulnerable to failure of fetal HSD2 expression in the brain. This should be considered when attempting therapeutic intervention against the neurodevelopmental effects of inappropriate glucocorticoid exposure. While pravastatin improves fetal outcomes when glucocorticoids exert their effects on the placenta, it remains to be seen if this is still the case when the fetus, and not the placenta, is exposed.

\section{Acknowledgement}

We would like to acknowledge funding from the Wellcome Trust (WT 07900) and the European Commission, Seventh Framework Programme (project acronym: DORIAN, grant agreement No. 278603). M.C.H. and F.S. are members of The University of Edinburgh Centre for Cognitive Aging and Cognitive Epidemiology, part of the cross-council Lifelong Health and Wellbeing Initiative (G0700704/84698). Funding from the BBSRC, the EPSRC, the ESRC and the MRC is gratefully acknowledged. F.J.G.S. is supported by a CCACE MRC PhD studentship We acknowledge the support of the UoE BHF Centre of Research Excellence.

\section{Statement of Ethics}

All animal experiments were approved by The University of Edinburgh Ethical Review Committee and studies were carried out in strict accordance with the UK Home Office Animals (Scientific Procedures) Act 1986 and the European Communities Council Directive of September 22, 2010 (directive 2010/63/EU).

\section{Disclosure Statement}

The authors have no conflict of interests to declare.

\section{References}

1 Barker DJ. Fetal origins of coronary heart disease. BMJ. 1995 Jul;311(6998):171-4.

2 Nomura Y, Wickramaratne PJ, Pilowsky DJ, Newcorn JH, Bruder-Costello B, Davey C, et al. Low birth weight and risk of affective disorders and selected medical illness in offspring at high and low risk for depression [Internet]. Compr Psychiatry. 2007 Sep-Oct; 48(5):470-8. Available from: http://www.scopus.com/inward/record.url? eid=2-s2.0 34547828854\&partnerID=tZOtx3y1.
3 Aarnoudse-Moens CS, Weisglas-Kuperus N, van Goudoever JB, Oosterlaan J. Meta-analysis of neurobehavioral outcomes in very preterm and/or very low birth weight children [Internet]. Pediatrics. 2009 Aug; 124(2):71728. Available from: http://Pediatrics.aappublications.org/cgi/doi/10.1542/peds.20082816

4 Leijon I, Ingemansson F, Nelson N, Wadsby $\mathrm{M}$, Samuelsson S. Reading deficits in very low birthweight children are associated with vocabulary and attention issues at the age of seven. Acta Paediatr. 2016 Jan;105(1):60-8.
5 Shenkin SD, Starr JM, Pattie A, Rush MA, Whalley LJ, Deary IJ. Birth weight and cognitive function at age 11 years: the Scottish Mental Survey 1932. Arch Dis Child. 2001 Sep;85(3):189-96.

6 Eide MG, Moster D, Irgens LM, ReichbornKjennerud T, Stoltenberg C, Skjærven R, et al. Degree of fetal growth restriction associated with schizophrenia risk in a national cohort. Psychol Med. 2013 Oct;43(10):2057-66.

7 Rifkin L, Lewis S, Jones P, Toone B, Murray R. Low birth weight and schizophrenia. Br J Psychiatry. 1994 Sep;165(3):357-62. 
8 Lampi KM, Lehtonen L, Tran PL, Suominen A, Lehti V, Banerjee PN, et al. Risk of autism spectrum disorders in low birth weight and small for gestational age infants [Internet]. J Pediatr. 2012 Nov;161(5):830-6.

9 Cottrell EC, Seckl JR. Prenatal stress, glucocorticoids and the programming of adult disease. Front Behav Neurosci. 2009 Sep;3:19.

10 Holmes MC, Abrahamsen CT, French KL, Paterson JM, Mullins JJ, Seckl JR. The mother or the fetus? 11beta-hydroxysteroid dehydrogenase type 2 null mice provide evidence for direct fetal programming of behavior by endogenous glucocorticoids [Internet]. J Neurosci. 2006 Apr;26(14):3840-4. Available from: http://www.jneurosci.org/cgi/doi/10.1523/ JNEUROSCI.4464-05.2006.

11 Slotkin TA, Kreider ML, Tate CA, Seidler FJ. Critical prenatal and postnatal periods for persistent effects of dexamethasone on serotonergic and dopaminergic systems [Internet]. Neuropsychopharmacology. 2006 May; 31(5):904-11. Available from: http://www. ncbi.nlm.nih.gov/pubmed/16160705.

12 Noorlander CW, Tijsseling D, Hessel EV, de Vries WB, Derks JB, Visser GH, et al. Antenatal glucocorticoid treatment affects hippocampal development in mice. PLoS One. 2014 Jan;9(1):e85671.

13 Cartier J, Zeng Y, Drake AJ. Glucocorticoids and the prenatal programming of neurodevelopmental disorders. Curr Opin Behav Sci. 2016;7:1-7.

14 Sarabdjitsingh RA, Loi M, Joëls M, Dijkhuizen RM, van der Toorn A. Early life stressinduced alterations in rat brain structures measured with high resolution MRI. PLoS One. 2017 Sep;12(9):e0185061.

15 Stirrat LI, Walker JJ, Stryjakowska K, Jones N, Homer NZ, Andrew R, et al. Pulsatility of glucocorticoid hormones in pregnancy: changes with gestation and obesity. Clin Endocrinol (Oxf). 2018 Apr;88(4):592-600.

16 Duthie L, Reynolds RM. Changes in the maternal hypothalamic-pituitary-adrenal axis in pregnancy and postpartum: influences on maternal and fetal outcomes. Neuroendocrinology. 2013;98(2):106-15.

17 Fowden AL, Li J, Forhead AJ. Glucocorticoids and the preparation for life after birth: are there long-term consequences of the life insurance? [Internet]. Proc Nutr Soc. 1998 Feb; 57(1):113-22. Available from: http://www. journals.cambridge.org/abstract S0029665198000202.

18 Chapman K, Holmes M, Seckl J. 11 $\beta$-hydroxysteroid dehydrogenases: intracellular gatekeepers of tissue glucocorticoid action [Internet]. Physiol Rev. 2013 Jul;93(3):1139-206. Available from: http://physrev.physiology. org/cgi/doi/10.1152/physrev.00020.2012.

19 Ballard PL, Ballard RA. Scientific basis and therapeutic regimens for use of antenatal glucocorticoids. Am J Obstet Gynecol. 1995 Jul; 173(1):254-62
20 Brown RW, Diaz R, Robson AC, Kotelevtsev YV, Mullins JJ, Kaufman MH, et al. The ontogeny of 11 beta-hydroxysteroid dehydrogenase type 2 and mineralocorticoid receptor gene expression reveal intricate control of glucocorticoid action in development. Endocrinology. 1996 Feb;137(2):794-7.

21 Diaz R, Brown RW, Seckl JR. Distinct ontogeny of glucocorticoid and mineralocorticoid receptor and 11beta-hydroxysteroid dehydrogenase types I and II mRNAs in the fetal rat brain suggest a complex control of glucocorticoid actions. J Neurosci. 1998 Apr;18(7): 2570-80.

22 Holmes MC, Sangra M, French KL, Whittle IR, Paterson J, Mullins JJ, et al. 11beta-Hydroxysteroid dehydrogenase type 2 protects the neonatal cerebellum from deleterious effects of glucocorticoids [Internet]. Neuroscience. 2006 Feb;137(3):865-73. Available from: http://www.sciencedirect.com/science/ article/pii/S0306452205010961.

23 Robson AC, Leckie CM, Seckl JR, Holmes MC. 11 Beta-hydroxysteroid dehydrogenase type 2 in the postnatal and adult rat brain. Brain Res Mol Brain Res. 1998 Oct;61(1-2): $1-10$.

24 Cottrell EC, Holmes MC, Livingstone DE, Kenyon CJ, Seckl JR. Reconciling the nutritional and glucocorticoid hypotheses of fetal programming [Internet]. FASEB J. 2012 May; 26(5):1866-74. Available from: http://www. fasebj.org/cgi/doi/10.1096/fj.12-203489.

25 Stirrat LI, Sengers BG, Norman JE, Homer NZ, Andrew R, Lewis RM, et al. Transfer and metabolism of cortisol by the isolated perfused human placenta. J Clin Endocrinol Metab. 2018 Feb;103(2):640-8.

26 Mark PJ, Waddell BJ. P-glycoprotein restricts access of cortisol and dexamethasone to the glucocorticoid receptor in placental BeWo cells. Endocrinology. 2006 Nov; 147(11): 5147-52.

27 St-Pierre M V, Serrano MA, Macias RIR, Dubs U, Hoechli M, Lauper U, Meier PJ, Marin JJ. Expression of members of the multidrug resistance protein family in human term placenta. Am J Physiol Regul Integr Comp Physiol. 2000;279:1495-503.

28 Lye P, Bloise E, Nadeem L, Gibb W, Lye SJ, Matthews SG. Glucocorticoids modulate multidrug resistance transporters in the first trimester human placenta. J Cell Mol Med. 2018 Jul;22(7):3652-60.

29 O'Donnell KJ, Bugge Jensen A, Freeman L, Khalife N, O'Connor TG, Glover V. Maternal prenatal anxiety and downregulation of placental 11 $\beta$-HSD2 [Internet]. Psychoneuroendocrinology. 2012 Jun;37(6):818-26.

30 Peña CJ, Monk C, Champagne FA. Epigenetic effectsofprenatalstresson $11 \beta$-hydroxysteroid dehydrogenase- 2 in the placenta and fetal brain. PLoS One. 2012;7(6):1-9.
31 New MI, Wilson RC. Steroid disorders in children: congenital adrenal hyperplasia and apparent mineralocorticoid excess [Internet]. Proc Natl Acad Sci USA. 1999 Oct;96(22): 12790-7. Available from: http://www.pnas. org/cgi/doi/10.1073/pnas.96.22.12790.

32 Debost JC, Petersen L, Grove J, Hedemand A, Khashan A, Henriksen T, et al. Investigating interactions between early life stress and two single nucleotide polymorphisms in HSD11B2 on the risk of schizophrenia. Psychoneuroendocrinology. 2015 Oct;60:18-27.

33 Li J, Chen YP, Wang ZN, Liu TB, Chen D, Dong YP, et al. A functional fetal HSD11B2[CA]n microsatellite polymorphism is associated with maternal serum cortisol concentrations in pregnant women. Kidney Blood Press Res. 2013;38(1):132-41.

34 Cottrell EC, Seckl JR, Holmes MC, Wyrwoll CS. Foetal and placental 11 $\beta$-HSD2: a hub for developmental programming [Internet]. Acta Physiol (Oxf). 2014 Feb;210(2):288-95. Availablefrom:http://doi.wiley.com/10.1111/ apha.12187.

35 Wyrwoll CS, Holmes MC. Prenatal excess glucocorticoid exposure and adult affective disorders: a role for serotonergic and catecholamine pathways. Neuroendocrinology. 2012;95(1):47-55.

36 Seckl JR, Meaney MJ. Glucocorticoid programming [Internet]. Ann N Y Acad Sci. 2004 Dec;1032(44):63-84. Available from: http:// www.ncbi.nlm.nih.gov/pubmed/15677396.

37 Bailey MA. 11ß-Hydroxysteroid Dehydrogenases and Hypertension in the Metabolic Syndrome. Curr Hypertens Rep. 2017 Nov; 19(12):100.

38 Bailey MA, Craigie E, Livingstone DEW, Kotelevtsev YV, Al-Dujaili EAS, Kenyon CJ, et al. Hsd1 1b2 haploinsufficiency in mice causes salt sensitivity of blood pressure. Hypertension. 2011 Mar;57(3):515-20.

39 Kalisch-Smith JI, Simmons DG, Dickinson H, Moritz KM. Review: sexual dimorphism in the formation, function and adaptation of the placenta. Placenta. 2017 Jun;54:10-6.

40 Burton GJ, Fowden AL, Thornburg KL. Placental Origins of Chronic Disease. Physiol Rev. 2016 Oct;96(4):1509-65.

41 Morsing E, Asard M, Ley D, Stjernqvist K, Marsál K. Cognitive function after intrauterine growth restriction and very preterm birth [Internet]. Pediatrics. 2011 Apr;127(4):e87482. Available from: http://Pediatrics.aappublications.org/cgi/doi/10.1542/peds.20101821.

42 Baschat AA. Neurodevelopment following fetal growth restriction and its relationship with antepartum parameters of placental dysfunction. Ultrasound Obstet Gynecol. 2011 May; 37(5):501-14.

43 Shapira-Zaltsberg G, Grynspan D, Quintana MV, Dominguez PC, Reddy D, Davila JH, et al. MRI features of the placenta in fetuses with and without CNS abnormalities [Internet]. Clin Radiol. 2018 Sep;73(9):836.e9-15. 
44 Basilious A, Yager J, Fehlings MG. Neurological outcomes of animal models of uterine artery ligation and relevance to human intrauterine growth restriction: a systematic review. Dev Med Child Neurol. 2015 May; 57(5):420-30

45 Perez-Garcia V, Fineberg E, Wilson R, Murray A, Mazzeo CI, Tudor $\mathrm{C}$, et al. Placentation defects are highly prevalent in embryonic lethal mouse mutants [Internet]. Nature. 2018 Mar;555(7697):463-8.

46 Bonnin A, Goeden N, Chen K, Wilson ML, King J, Shih JC, et al. A transient placental source of serotonin for the fetal forebrain [Internet]. Nature. 2011 Apr;472(7343):347-50.

47 Nugent BM, O'Donnell CM, Neill Epperson C, Bale TL. Placental H3K27me3 establishes female resilience to prenatal insults. Nat Commun. 2018;9:1-10.

48 Chan JC, Nugent BM, Bale TL. Parental Advisory: Maternal and Paternal Stress Can Impact Offspring Neurodevelopment [Internet]. Biol Psychiatry. 2018 May;83(10):886-94.

49 Marsit CJ, Maccani MA, Padbury JF, Lester BM. Placental 11-beta hydroxysteroid dehydrogenase methylation is associated with newborn growth and a measure of neurobehavioral outcome. PLoS One. 2012; 7(3):e33794.

50 Zhao Y, Gong X, Chen L, Li L, Liang Y, Chen $\mathrm{S}$, et al. Site-specific methylation of placental HSD11B2 gene promoter is related to intrauterine growth restriction [Internet]. Eur J Hum Genet. 2014 Jun;22(6):734-40.

51 Hewitt DP, Mark PJ, Waddell BJ. Glucocorticoids prevent the normal increase in placental vascular endothelial growth factor expression and placental vascularity during late pregnancy in the rat. Endocrinology. $2006 \mathrm{Dec}$ 147(12):5568-74.

52 Hewitt DP, Mark PJ, Waddell BJ. Placental expression of peroxisome proliferator-activated receptors in rat pregnancy and the effect of increased glucocorticoid exposure [Internet]. Biol Reprod. 2006 Jan;74(1):23-8. Available from: https://academic.oup.com/biolreprod/article-lookup/doi/10.1095/biolreprod.105.045914.
53 Wyrwoll CS, Seckl JR, Holmes MC. Altered placental function of 11beta-hydroxysteroid dehydrogenase 2 knockout mice. Endocrinology. 2009 Mar;150(3):1287-93.

54 Wyrwoll CS, Noble J, Thomson A, Tesic D, Miller MR, Rog-Zielinska EA, et al. Pravastatin ameliorates placental vascular defects, fetal growth, and cardiac function in a model of glucocorticoid excess [Internet]. Proc Natl Acad Sci USA. 2016 May;113(22):6265-70. Available from: http://www.pnas.org/lookup/doi/10.1073/pnas.1520356113.

55 Neuvonen PJ, Backman JT, Niemi M. Pharmacokinetic comparison of the potential over-the-counter statins simvastatin, lovastatin, fluvastatin and pravastatin. Clin Pharmacokinet. 2008;47(7):463-74.

56 Ahmed A, Singh J, Khan Y, Seshan SV, Girardi G. A new mouse model to explore therapies for preeclampsia. PLoS One. 2010 Oct; 5(10):e13663.

57 Garrett N, Pombo J, Umpierrez M, Clark JE, Simmons M, Girardi G. Pravastatin therapy during preeclampsia prevents long-term adverse health effects in mice. JCI Insight. 2018 Apr;3(8):120147.

58 Wyrwoll C, Keith M, Noble J, Stevenson PL, Bombail V, Crombie S, et al. Fetal brain $11 \beta$-hydroxysteroid dehydrogenase type 2 selectively determines programming of adult depressive-like behaviors and cognitive function, but not anxiety behaviors in male mice. Psychoneuroendocrinology. 2015 Sep;59:5970.

59 Rosenfeld CS. Sex-specific placental responses in fetal development. Endocrinology. 2015 Oct; 156(10):3422-34.

60 Appleton AA, Armstrong DA, Lesseur C, Lee J, Padbury JF, Lester BM, et al. Patterning in placental 11-B hydroxysteroid dehydrogenase methylation according to prenatal socioeconomic adversity. PLoS One. 2013 Sep; 8(9):e74691.

61 Bonnin A, Torii M, Wang L, Rakic P, Levitt P. Serotonin modulates the response of embryonic thalamocortical axons to netrin-1. Nat Neurosci. 2007 May;10(5):588-97.
62 Hendricks TJ, Fyodorov DV, Wegman LJ, Lelutiu NB, Pehek EA, Yamamoto B, et al. Pet-1 ETS gene plays a critical role in 5-HT neuron development and is required for normal anxiety-like and aggressive behavior. Neuron. 2003 Jan;37(2):233-47.

63 St-Pierre J, Laurent L, King S, Vaillancourt C. Effects of prenatal maternal stress on serotonin and fetal development. Placenta. 2016 Dec;48:S66-71.

64 Van den Hove DL, Lauder JM, Scheepens A, Prickaerts J, Blanco CE, Steinbusch HW. Prenatal stress in the rat alters 5-HT1A receptor binding in the ventral hippocampus. Brain Res. 2006 May; 1090(1):29-34.

65 Medeiros LR, McDonald MD. Cortisol-mediated downregulation of the serotonin $1 \mathrm{~A}$ receptor subtype in the Gulf toadfish, Opsanus beta [Internet]. Comp Biochem Physiol A Mol Integr Physiol. 2013 Apr;164(4):612-21.

66 Chalmers DT, Kwak SP, Mansour A, Akil H, Watson SJ. Corticosteroids regulate brain hippocampal 5-HT1A receptor mRNA expression [Internet]. J Neurosci. 1993 Mar; 13(3):914-23. Available from: http://www. ncbi.nlm.nih.gov/pubmed/8441016.

67 Bonnin A, Peng W, Hewlett W, Levitt P. Expression mapping of 5-HT1 serotonin receptor subtypes during fetal and early postnatal mouse forebrain development. Neuroscience. 2006 Aug; 141(2):781-94.

68 Meijer OC, Cole TJ, Schmid W, Schütz G, Joëls M, De Kloet ER. Regulation of hippocampal 5-HT1A receptor mRNA and binding in transgenic mice with a targeted disruption of the glucocorticoid receptor. Brain Res $\mathrm{Mol}$ Brain Res. 1997 Jun;46(1-2):290-6.

69 Räikkönen K, Pesonen AK, O’Reilly JR, Tuovinen S, Lahti M, Kajantie E, et al. Maternal depressive symptoms during pregnancy, placental expression of genes regulating glucocorticoid and serotonin function and infant regulatory behaviors. Psychol Med. 2015 Nov; 45(15):3217-26.

70 Bronson SL, Chan JC, Bale TL. Sex-Specific Neurodevelopmental Programming by Placental Insulin Receptors on Stress Reactivity and Sensorimotor Gating [Internet]. Biol Psychiatry. $2017 \mathrm{Jul} ; 82(2): 127-38$. 